\title{
Teaching Developmental Theory with Interrupted Video Case Studies
}

\author{
Bill Anderson \\ Illinois State University
}

\begin{abstract}
This study sought to determine the usefulness of interrupted case studies, utilizing a progressive disclosure of information over time, to increase critical thinking and student learning in the study of foundational theories in the human development field. Apted's (2013) Up documentary series, consisting of video interviews over a 49-year period, was used as the interrupted study and successfully provided vicarious, but meaningful, opportunities to consistently and authentically apply course content. Participants $(N=23)$ were students in three sections of a graduate Human Development course where a pre-/ post-test format was utilized. The effect was significant as all participant's posttest score improved an average of $24.3 \%, F(3,19)=3.55, p=.049$. Also, coded student work indicated an increase in complex levels of thinking across the 8-week assignment, further validating post-test scores, $t(352)=-3.172, p=.002$. Evidence from student work. further confirmed that an interrupted video case-study, could address limitations typically associated with case-based instruction and, more importantly, provide the critical case-study qualities needed here. Those included, telling a detailed, ambiguous, and real-life story that provided genuine context to connect theory and practice.
\end{abstract}

Keywords: Case-based instruction, video, developmental theory

\section{Introduction}

The lasting value of fundamental course content is largely as a means to deeper learning, successfully applying that content to problem-solving, and transferring this knowledge to future, more meaningful applications (Ambrose, Bridges, DiPietro, Lovett, \& Norman, 2010). Quite often then the most significant improvement teachers can make is to provide students more authentic observation and application experiences linked to the subject material. Yet less class time is typically available for this more meaningful, real-world learning (Mayall, 2010). When such application is impractical or impossible, other forms of doing and observing can be of value (Fink, 2003). Case-based instruction (CBI) has repeatedly been found to help generate opportunities to apply content that students might not otherwise have in business (Herreid, 2011), psychology (Mayo, 2002), engineering (Brooks, Jyothsna, \& Mehmet, 2012), law (Harvard Law School, 2014), and teacher education (Harrington, 1995). CBI has also been reported to transcend the information of any single classroom (John, 2002) and promote critical thinking (Herreid, Schiller, \& Herreid, 2012; Kantar, 2013, McFarlane, 2015), involving thought and action in both specific and general terms (John, 2002).

However, tangible learning outcomes with CBI have received only moderate attention (White et al., 2009). Also, and though others have found it valuable in graduate education to specifically increase critical thinking and engage in more authentic learning (e.g. Casotti, Beneski, \& Knabb, 2013; Kantar, 2013; Ulanoff et al., 2009), existing research concerning CBI in graduate education is likewise limited. Also of interest to this study is Mayo's (2004) assertion that "a promising direction for casebased instruction might involve the combination of video technology and case method of teaching" (p. 144). An idea reiterated more recently by Brooks et al. (2012) and Mayall (2010) but, as with CBI in general, with little empirical work. 


\section{Literature Review}

Evidence suggests that utilizing case studies that explicitly require solutions or explanations can serve as an effective means of utilizing and reinforcing explanatory theories (Egleston, 2013; Mayo, 2004; McFarlane, 2015). Teaching students to choose and appropriately apply theoretical models helps them to intentionally relate theory to practical situations and to better understand how professionals develop and articulate their ideas (Herreid, 2012; Noorminish, Mirabolghasemi, Mustaffa, Latif, \& Buntat, 2013). Unfortunately, "many students do not make the important connections between and among the facts they learn in classrooms and the larger system of ideas reflected in an expert's knowledge of the discipline" (Anderson \& Krathwohl, 2001, p. 42). With CBI, students can discuss their analyses, prioritize their findings, suggest solutions and possible consequences, provide evidence, and critique and refine their solutions (Harrington, 1995). During this time they also receive, process, and understand feedback.

The qualities of a good case study are many and certainly vary with teaching goals. But even those that may appear as common sense could be overlooked, such as simply being pertinent to the class and learning objectives (McFarlane, 2015). Other qualities less often considered but most relevant to this study include:

- connects theory and practice (Anderson, Bradshaw, \& Banning, 2016; Penn, Currie, Hoad, \& O’Brien, 2016; Prud'homme-Genereauz, 2017)

- serves as "a context for making meaning of concepts presented during instruction... thus making understanding transparent" (Ulanoff, Fingon, \& Beltran, 2009, p. 125)

- tells a focused story and utilizes a detailed person-in-context setting where learners understood that they were watching a real person (Ruggiero, 2002)

- contains reasonable and realistic ambiguity (BU Center for Excellence and Innovation in Teaching, 2015; Ruggiero, 2002)

However, case studies are not without recognized limitations. For instance, when students are unfamiliar with $\mathrm{CBI}$ it may require a greater intentionality on the part of the instructor in introducing the assignment (Penn et al., 2016). Also, if the student is simply presented with a case study and provided with a set of questions, what is very likely being assessed is simply the student's ability to locate predetermined answers directly available within the case. Consequently, "students do not learn where to go to ask the appropriate questions; they learn to answer those asked by others... they learn that the answers are in front of them" (Egleston, 2013, p. 101). Furthermore, many currently available cases have student responses, instructor write-ups, and class presentations readily obtainable online. Mayo (2004) also reported that most case studies are limited in length and therefore may relate to only a few course concepts. Finally, CBI can become a largely passive activity (Herreid, 2005), perhaps especially for students who perceive the activity as busy work (Hodges, 2005) or fail to develop empathy with the characters and situation presented (McFarlane, 2015).

Still, CBI can, with time and purposeful planning, cast the learner in the more desired active role, using "course relevant ideas and explanations to frame the case problem, to analyze it, and to explain its causes... using contextual variables in a meaningful way" (Riggiero, 2002, p. 115). At that point, they are certainly practicing the role of professional (Noorminish et al., 2013), and transferring course content to real-life contexts (Penn et al., 2016; Ruggiero, 2002). Surely students learn more when they are authentically engaged in a process (Egleston, 2013) that is "not hierarchical but rather relational and even interactive" (Fink, 2003, p. 32).

Journal of the Scholarship of Teaching and Learning, Vol. 19, No. 5, December 2019. josotl.indiana.edu 


\section{The Interrupted Case Study}

In 1994, Irby described a method for addressing the above limitations and moving learners to the desired more active role. With case-iterative teaching, predetermined bits of information are presented in the order in which they originally occurred and students were then asked to think aloud and advance the examination of evidence. Interpretation, serial questioning, and justification continued until all relevant information had been shared or a consensus had been reached. In addition to being more active, this method also addressed a previously mentioned limitation as the case is developed in real time with no readily available answers for students to cite or easily download (e.g. Egleston, 2013). Others have more recently described successful teaching and learning where the case is given to students in selected, organized parts (e.g. Brooks et al. 2012; Herreid, 2012; White et al., 2009). This interrupted case study (ICS) also uses a stepwise disclosure of information rather than revealing the entire story line at the outset, has ambiguities, but requires more time to give a necessary richness to the unfolding story (Brooks et al., 2012; Herreid, 2007). Students begin with incomplete data, create tentative hypotheses, gather more information, refine their hypotheses, predict, consider new information, and continue "to refine their thoughts and processes as additional data is received" (Brooks et al., 2012, p. 2). It is rather a progressive discovery viewed as problem-based learning over time with the learner never knowing how it will all play out and requires some speculation and risktaking on the student's part. This format has been successful in part because it provides additional structure to the conversation, an important point for those students who do not readily engage in an unrestricted, exploratory discussion (Herreid, 2011). Additionally, the interrupted approach allows instructors multiple opportunities to pose questions, review student responses, and use those responses to address student misconceptions (e.g. Prud'homme-Genereauz, 2017).

However, when using an interrupted format, the instructor must risk no longer being the final authority, but rather a facilitator, guiding a more flexible discussion at a varying pace (Brooks et al., 2012), guiding students in "the direction of inferences and conclusions, rather than providing them with ready-made answers" (Mayo, 2004, p. 143). As "critical thinking can't be just the content of the discipline but must also be the way we go about problem-solving and asking questions" (Herreid et al., 2012, p. 21), it is the student who must lead such learning (Herreid, 2011; Kantar, 2013). Of course, students still employ textbook material and call upon personal experience (Egleston, 2013), but they are again encouraged to think aloud, essentially rehearsing professional thinking (e.g. Fink, 2003; Irby, 1994), and even to infer and imagine future consequences from the case (Anderson, Jorns, \& Bivens, 2017; Herreid, 2011). Although effective teaching is always more than a simple information exchange, if the instructor is any less directive with ICS, students could possibly perceive cases as an artificially burdensome way of learning.

\section{Purpose of this study}

This study sought to examine the following points. First, to assess the usefulness of a unique interrupted form of CBI to increase critical thinking (e.g. Casotti et al., 2013; Kantar, 2013; Ulanoff et al., 2009). Indeed, as "factual knowledge exists at a relatively low level of abstraction" (Anderson \& Krathwohl, 2001, p. 45), it seems likely that more complex thinking would yield improvement in student learning. Secondly, to determine if Apted's (2013) Up Series documentary could function as a fitting case study with this course material, provide Fink's (2003) meaningful vicarious opportunities to apply course content, and demonstrate the essential qualities of CBI previously mentioned.

Journal of the Scholarship of Teaching and Learning, Vol. 19, No. 5, December 2019. josotl.indiana.edu 


\section{Methods}

Participant were 23 female students enrolled in three annual sections of a graduate course pertaining to human development and culture. All were first-year graduate students and most were pursuing degrees in Human Development or Child Life Specialization $(N=18)$. Other fields of study represented included one student each from: counseling, nursing, kinesiology, developmental psychology, and social work.

\section{ICS application}

The Up Series documentary (Apted, 2013) was used as an ICS assignment. This longitudinal series of interviews follows several individuals from 1963, at age seven, revisiting them every seven years until 2013, at age 56. Because of time constraints, four of the individuals in the film were selected by the class and professor in each class, with one or two students assigned specifically to follow each of those participants selected. Although the entire class would view each of the selected participants each week and were free to discuss each other's findings and questions as well as their own. Working with interview data at each age, students used the assumptions, concepts, and terminology of relevant developmental theory to make tentative predictions of who this child might be when they saw them at the next age. Students then continued to view the selected individuals over an eight-week period, not progressing to the next participant age until the next class meeting.

In weekly reflective essays, students anticipated growth and change in the developing participants. These essays included student's reviews of their most recent predictions, current descriptions of the assigned individuals, and their new predictions for the next seven years utilizing appropriate developmental theories and terminology. Each consecutive week, students shared their predictions for the target age with the class and then viewed the documentary participants at the new age, 14, 21, 28, 35, 42, 49, and 56. Using new information and shared insight, students refined their work, and made the next set of predictions.

\section{Analysis}

A case study format was used as it is particularly suited to examine educational process and change over time (McKinney, 2007) and to illustrating causation research (Krathwohl, 2009; Yin, 2009). However, because case studies in education typically focus on a single course or assignment results are often difficult to perceive objectively (Bishop-Clark \& Dietz-Uhler, 2012; McKinney, 2007). Consequently, triangulation is more necessary in case-study research than with other designs (Krathwohl, 2009; Yin, 2003) in order to clarify the findings and result in "a better, richer, and more complete picture" (Bishop-Clark \& Dietz-Uhler, 2012, p. 59). Others have reported that triangulation is also a necessary, but underused, element in studies of teaching and learning (Divan, Ludwig, Matthews, Motley, \& Tomljenovic-Berube, 2017). Krathwohl's (2009) model of triangulation as a multimethod-multimeasure procedure was applied here, utilizing three independent measures, described in more detail below, to reveal any potential redundancy in the data (e.g. Divan et al., 2017; Krathwohl, 2009). Accordingly, three classes, replicated across time, were also used to examine the same learning outcome.

\section{Pre-/Post-test}

Because the low number of participants could clearly result in low statistical power, a repeated measures pre-posttest design was utilized across three equivalent replications (Bishop-Clark \& Dietz- 
Uhler, 2012; Wilson-Doenges, 2013). This design would also serve to moderate selection bias and better support internal validity as students are compared only to themselves (Bartsch, 2013). A pretest consisting of 39 understanding/applying level (e.g. Anderson \& Krathwohl, 2001), multiplechoice questions was administered before the first showing of 56-Up in class. The test questions related solely to human developmental theory (Piaget, Erikson, Bronfenbrenner), cognitive development (Perry), and motivation (expectancy/value theory, motivational sequence). An identical post-test was given at the completion of the ICS assignment.

A univariate ANOVA was used to determine significant difference between pre-test scores in the three classes. Next the difference between pre- and post-test scores was determined utilizing an ANCOVA to control for the pre-test score. Finally, as recommended by Wilson-Doenges (2013), a series of paired samples $t$-tests were used to compare pre-/post- results within the three individual cohorts.

\section{Coding}

Student essays \#2, at target age 14, and \#8, at age 56, containing student's review of their most recent predictions, descriptions of the target individuals at the new age using appropriate theories, and their predictions for the next seven years, were coded line-by-line to determine agreement with a predetermined pattern (e.g. Yin, 2003, 2009). Essentially, the goal was to explain relationships between data by comparing an expected theoretical pattern with an observed pattern, in this case with the pre/post results. However, pattern-matching here varied slightly from the original idea of generating an expected, conceptual pattern from existing literature (Almutairi, Gardner, \& McCarthy, 2014; Yin, 2009), to utilizing an established educational pattern with Bloom's Revised Taxonomy (Anderson \& Krathwohl, 2001). It was anticipated that the coding would reveal more complex reasoning in essay \#8 (e.g. Valcke, De Wever, Zhu, \& Deed, 2009) and that this increase would agree with changes in the post-test results.

Descriptors for each taxonomy level, derived from the Quick. Flip Questions for the Revised Blooms Taxonomy (2001) and listed in Table 1 below, were also used to better clarify coding concepts. This same procedure had previously worked successfully both in the pilot of the current study (Anderson et al., 2016) and later in assessing the efficacy of concept mapping in undergraduate classes (Law, Meyer, \& Fall, 2016).

\section{Table 1. Student Essay Coding Scheme

Code Taxonomy level Example descriptors \\ 1 Remembering tell, recall, relate, label, who, when, where \\ 2 Understanding explain, summarize, relate, rephrase, compare, contrast \\ 3 Applying identify, apply, utilize, organize, develop, make use of \\ 4 Analyzing analyze, compare, distinguish, simplify, categorize \\ 5 Evaluating interpret, prioritize, disprove, justify, value, conclude \\ 6 Creating predict, elaborate, imagine, combine, originate, propose}

Intercoder reliability of two independent coders was refined over two reviews of the student essays and determined by using the intra-class correlation coefficient function of SPSS v.20 to determine a kappa score of reliability. A score of .80 was deemed reliable (Bishop-Clark \& Dietz-Uhler, 2012). A paired samples t-test was used to compare initial and final essays from the three classes collectively and a series of paired samples $t$-tests to compare the three classes.

Journal of the Scholarship of Teaching and Learning, Vol. 19, No. 5, December 2019.

josotl.indiana.edu 


\section{IDE A Student Evaluations}

The three course sections reflected here were each evaluated by all students using the Individual Development and Educational Assessment instrument (IDEA, 2017), designed to specify progress on relevant teaching objectives. Results are reported on a 5-point scale as follows: $1=$ No apparent progress; 2 = Slight progress; $3=$ Moderate progress; $4=$ Substantial progress; $5=$ Exceptional progress. Each rating is presented in an unadjusted and an adjusted form. The unadjusted score, used here, does not reflect factors beyond the instructor's control that may influence student ratings (i.e. student effort not attributable to the instructor or course, difficulty not attributable to the instructor). Items deemed relevant for examination here include the following IDEA (2018) learning objectives:

\section{- Learning to analyze and critically evaluate ideas, arguments, and points of view}

- Acquiring an interest in learning more by asking my own questions and seeking answers

- Found ways to answer my own questions

The student rating on the above items for the three years of this study will be compared to the previous three years of IDEA ratings of the course that had not used the Up-Series (Apted, 2013) as an ICS utilizing a paired-samples $t$-test.

\section{Results}

Pre-/post-test

For all participants the posttest score was higher, moving from a pretest mean of 17.96/39 (SD - 1.00) to a posttest mean of 27.43/39 (SD - .874). A univariate ANOVA resulted in no statistically significant difference in pre-test scores between the three classes, $F(2,20)=.496, p=.616$. Analysis with an ANCOVA revealed a significant improvement from pre- to post-test, $F(3,19)=3.55, p=.049$. A series of paired sample $t$-tests, Table 2 below, showed that the effect was significant for each cohort as well.

Table 2. Pre-/post-test scores

\begin{tabular}{l|lllll} 
Class & $n$ & Pre-test $M(S D)$ & Post-test $M(S D)$ & Change & Significance \\
\hline 2015 & 7 & $18.86 / 39(3.761)$ & $26.43 / 39(3.505)$ & $+19.4 \%$ & $t(6)=-7.990, p=.000$ \\
2016 & 8 & $18.13 / 39(3.907)$ & $27.88 / 39(4.454)$ & $+25.0 \%$ & $t(7)=-8.899, p=.000$ \\
2017 & 8 & $16.88 / 39(4.051)$ & $28.00 / 39(4.175)$ & $+28.5 \%$ & $t(7)=-16.803, p=.000$
\end{tabular}

\section{Coded Essays}

Following coding, the intra-class correlation coefficient function of SPSS v. 20 determined a kappa score of inter-rater reliability of .846 for essay \#2 and .818 for essay \#8. Results indicated a movement toward higher level thinking on the taxonomy in each of the three classes, with a greater reliance on evaluating and creating in the final essay. 
Table 3. Results of student essay coding for each class

$\begin{array}{lllllll}\text { Coding Level } & 2015 \text { \#2 } & 2015 \text { \#8 } & 2016 \text { \#2 } & 2016 \text { \#8 } & 2017 \text { \#2 } & 2017 \text { \#8 } \\ \text { Creating \% } & 9.6 & 12.2 & 6.7 & 12.3 & 1.5 & 9.9 \\ \text { Evaluating \% } & 9.7 & 12.2 & 8.8 & 24.1 & 15.9 & 18.3 \\ \text { Analyzing \% } & 15.9 & 28.6 & 19.8 & 6.1 & 15.9 & 16 \\ \text { Applying \% } & 12.4 & 5.5 & 14.1 & 11.8 & 19.5 & 14.3 \\ \text { Understanding \% } & 17.9 & 8.8 & 27.7 & 19.8 & 27.2 & 15.3 \\ \text { Remembering \% } & 34.5 & 32.7 & 26.6 & 25.9 & 20.0 & 26.2\end{array}$

Considering the three classes together, Table 4 also shows an overall decrease in understanding and applying responses and an increase in evaluating and creating level responses in essay \#8.

Table 4. Total Coded Essay Responses

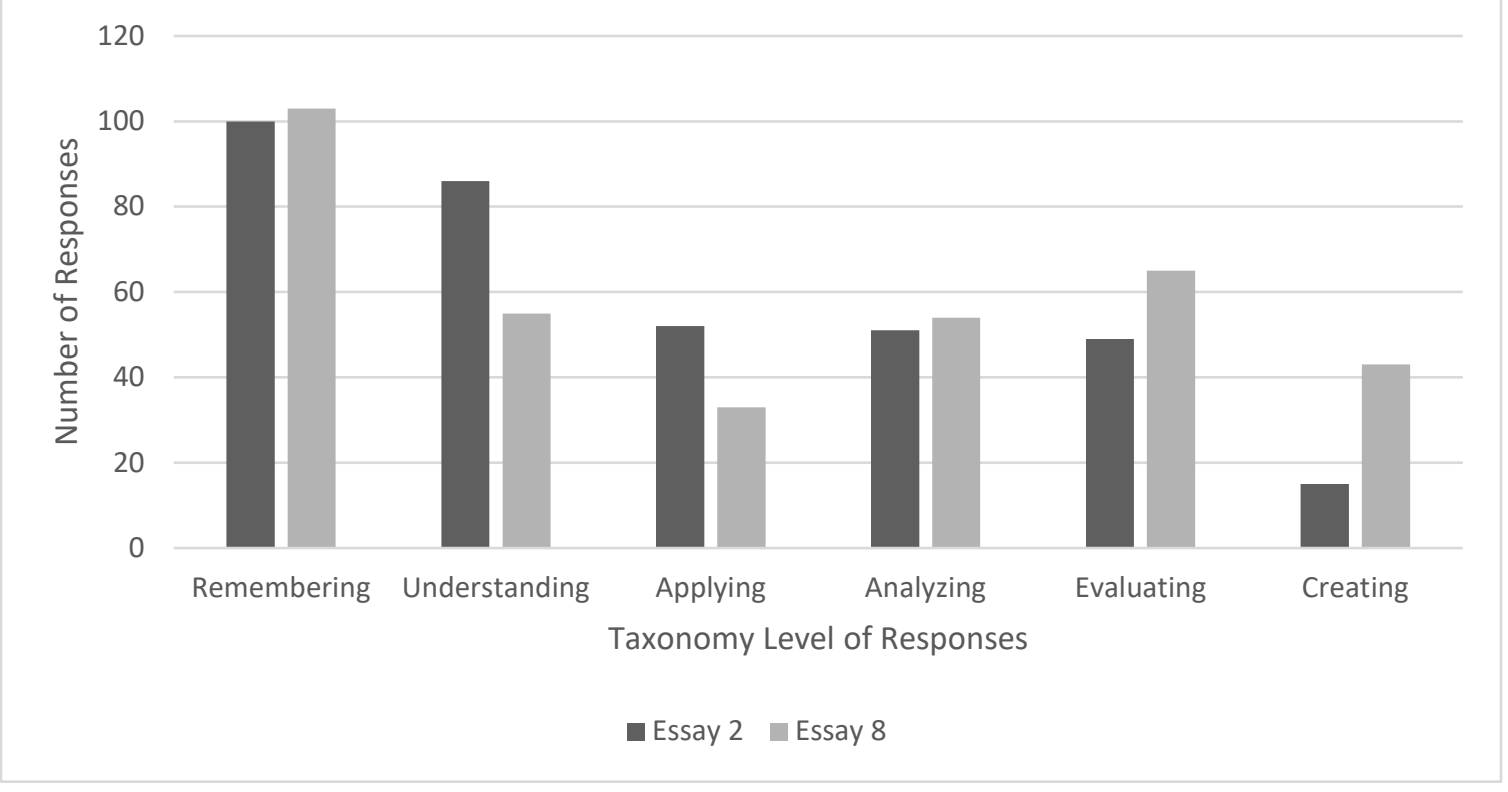

Results of a paired samples t-tests revealed that overall differences from essay $2(M=2.74$, $S D=1.548)$ to the final essay $(M=3.15, S D=1.816)$ were statistically significant when all three classes were combined, $t(352)=-3.172, p=.002$. Next, a series of paired samples $t$-tests were used to examine more specific changes in coding involving the total sample. Results showed that although statements at the remembering level did not change significantly, $t(2)=-.493, p=.671$, responses at the understanding level dropped significantly from essay $2(M=24.267, S D=5.52)$ to essay $8(M=$ 14.633, $S D=3.19), t(2)=8.129, p=.015$. Similarly, those at the applying level also decreased from essay $2(M=15.333, S D=3.71)$ to the final essay $(M=10.533, S D=4.534)$, approaching significance, $t(2)=3.574, p=.070$. Statements at the analyzing level, with an essay 2 mean of $17.2(S D=2.517)$ and an essay 8 at $16.9(S D=11.277)$, showed no significant change, $t(2)=.039, p=.972$. Although evaluating level responses were used more in the final essay in each of the three classes, moving from $M=11.467(S D=3.866)$ to $M=18.2(S D=5.951)$, the difference was not significantly significant, $t(2)=-1.572, p=.257$. Responses at the creating level increased most noticeably, moving from $M=$ 
$5.93(S D=4.104)$ to $M=11.467(\mathrm{~S} D=1.358)$ and approached statistical significance, $t(2)=-3.304$, $p=.081$.

\section{IDE $A$ student ratings}

Each of the previously identified IDEA (2018) learning objectives were compared to the previous three years of IDEA ratings for the course that had not used the Up-Series (Apted, 2013) as an ICS. Most showed a slight improvement.

- Learning to analyze and critically evaluate ideas, arguments, and points of view, improved from $M=$ 4.67/5.0 (SD =.153) to $M=4.83 / 5.0(S D=.208)$. Results were significant, $t(2)=-5.00, p .=$ .038

- Acquiring an interest in learning more by asking my own questions and seeking answers, improved from $M=4.37 / 5.0(S D=.231)$ to $M=4.63 / 5.0(S D=.305)$, with results approaching significance $t(2)=-4.00, p .=.057$

- Found ways to answer my own questions showed no change at $4.84 / 5.0$

\section{Discussion}

Results indicated an increase in student learning for all participants with an average increase in posttest performance of 24.3\%. Coding of student essays with Anderson and Krathwohl's (2001) revised taxonomy supported the posttest improvement with an indicated student movement toward a more complex thinking. More specifically, students utilized understanding (explain, summarize, rephrase) and applying (identify, utilize, organize) less and increased their use of creating (predict, elaborate, propose). It seems likely that both of these results are, at least in part, the consequence of students having opportunities to actually apply theory, evaluate their application, process feedback, and refine their position over time. Therefore, these findings support existing research that suggests utilizing ICS that require solutions or explanations can serve as an effective means of applying and reinforcing explanatory theories (Egleston, 2013; Mayo, 2004; McFarlane, 2015; Prud'homme-Genereauz, 2017). This is further evidenced in the following student responses:

Suzy listened to her parents and did what was expected of a child in her environment. Now that she is an adult... Foreclosure? Isolation?

Nicolas demonstrated a form of thinking between relativism and commitment... couldn't that relate to the person's developmental niche?

Nicholas is already showing Perry's commitment... [he] states that the individual looks at priorities and commits fully to one; however if convinced, may be inclined to change his or her mind.

Results here also supported the idea that teaching students to choose and appropriately apply theoretical models helps to intentionally relate theory to practical situations and leads to better understanding how professionals in the human development and family science field advance and communicate their ideas (e.g. Herreid, 2012; Noorminish et al., 2013). Related student responses included: 
She has such short-term goals that she is not attempting to prioritize thinking. I found this interesting because, just as Piaget's stages (formal thinking) were linked to Erikson's stages (identity), I now think that Perry's reflective judgment should be as well.

I am now linking [expectancy*value] motivation with the stages of psychosocial development and the developmental niche.

Overall, my work evolved from basic understanding and knowledge, to the creation of new ideas, finishing with unanswered questions.

Although findings from the IDEA ratings comparisons were less robust compared with those from the pre-/post-test and coding, results indicated a subtle improvement in the area of considering and evaluating other's perspectives, certainly critical to the ICS assignment. Perhaps this was related to the evaluating/creating level descriptors previously mentioned. Support from student observations included:

I am better able to understand that I must examine an individual's culture in order to fully understand them as a person. I am a little surprised as I look back at some of my earlier work. I was so confident but using so little information.

A second trend I noticed while reviewing my work from this semester involved considering between and within group differences.

The second goal was to ascertain if the Up-Series (Apted, 2013) could meet the needs of teaching developmental theory as a video case study (e.g. Brooks, et al., 2012; Mayall, 2010; Mayo, 2004). Results here indicate that the video interviews served successfully in this role, and also illustrated that the ICS met several standards of CBI. Specifically, it was pertinent to the class learning objectives (McFarlane, 2015), encouraged retention (Penn et al., 2016), and consistently linked theory and practice (Penn, Currie, Hoad, \& O’Brien, 2016; Prud'homme-Genereauz, 2017). The series addressed a number of other essential CBI qualities as well.

First, recall that Ulanoff et al. (2009) described cases as teaching tools that make learning more accessible by serving as frameworks for student meaning-making. In this case, following the participants (Apted, 2013) over a 49 year period provided authentic context for understanding (e.g. Ulanoff et al., 2009) developmental theory. Student remarks included:

Commitment in relativism is recognizing choices, accepting responsibility and consequences, and willingness to accept others' right to their choices. Suzy shows full recognition that choices restrict some choices and open the way to others. She may continue to reaffirm or reject old beliefs; either way, the decision is based on a conscious consideration of alternatives. She is no dualist!

I began the course being able to criticize others' ideas and research, provide specific evidence regarding why I made certain predictions, and be curious about and interested in the experience of others in a different culture. I ended the course feeling confident in my ability to seek and find an answer to my own questions.

Journal of the Scholarship of Teaching and Learning, Vol. 19, No. 5, December 2019. josotl.indiana.edu 
Next, this person-in-context setting element of CBI must communicate a detailed and focused human story (Ruggiero (2002), engaging and meaningful to students (Herreid 2007; Mayo, 2004). Apted's (2013) interviews allowed students to discover and understand "that, for someone else, this dilemma is very real" (Ruggiero, 2002, p. 120) and confirmed Herreid's (2007) statement, "there is no better way to understand a situation and to gain empathy for the characters than to hear them speak in their own voices" (p. 46). Students here regularly responded with interest, insight, and sometimes concern.

I had worried about Bruce every week, despite his continued success as a teacher. But last week, seeing his wedding (finally) I actually cried a little in class, but I wasn't the only one.

Neil (at 56) said that he was absolutely sure that his faith helped him through difficult times... [and] again shows signs of, I believe, generativity. But then we have been describing Neil this way since he was 28 haven't we?

I would like to predict that his life becomes a little more stable, but I'm not sure if that is a true prediction or just my hope.

Lastly, CBI is made more authentic with the inclusion of realistic ambiguity and uncertainty (BU Center for Excellence and Innovation in Teaching, 2015; Ruggiero, 2002). With the presence of this quality, students "never know how it will all come out..." (Herreid, 2007, p. 48). Evidence from students included:

The more I watch these episodes, the more I realize that anything can happen in a seven year span.

Was Neil simply more reflective at 14 , as I had thought, or did I actually miss something that would have let me accurately predict Neil at 21? Was I thinking theory or not seeing past what I was hoping for Neil.

I might be thinking this way because of the way I feel about my parents... assuming his experience is reflective of mine. I think that the distance Neil has with his family might be for a reason that we have yet to see in his interviews. He seemed less poetic... I got the impression that he might be using a drug therapy to manage... I also didn't really see the "sparkle of the 7-year old eyes." It felt like meeting a whole new person... I hope he remains in good health, but I am worried.

\section{Conclusion}

The use of the interrupted video case study format was successful in satisfying the first goal of this study, resulting in increased critical thinking (Herreid, 2012; Brooks et al., 2012; White et al., 2009) and better learning and retention (McFarlane, 2015; Penn et al., 2016). Indeed, the interrupted format encouraged decision making and explanation building (e.g. Ruggiero, 2002), and guided students toward progressive, step-wise inferences, rather than singular, ready-made conclusions (Mayo, 2004). The independent and varied methods used here, considered as a multimethod-multimeasure procedure (Krathwohl, 2009), resulted in a clear, triangulated support (e.g. Krathwohl, 2009; Yin, 2003, 2014) of student learning anchored in the ICS curriculum. Results also support the idea that 
CBI is beneficial in graduate education by specifically increasing critical thinking (e.g. Casotti et al., 2013; Kantar, 2013; Ulanoff et al., 2009).

Concerning the second goal, Apted's (2013) Up-Series effectively provided authentic opportunities (e.g. Fink, 2003) to apply theory (e.g. Prud'homme-Genereauz, 2017), and met all necessary requirements for an effectual CBI. Unlike cases that are typically more limited in length and scope, relating to only some course concepts (e.g. Mayo, 2004), Apted's (2013) documentary covers 49 years of observations and interviews of people of varied gender, ethnicity, and socio-economic status. Furthermore, the series is interrupted by design and easily provided a consistent, unfolding story of participant's lives. The resulting inevitability of reevaluating and reorganizing previous learning and information appears to have allowed students to "disentangle the normative (what ought to be) and the operative (what is)" and "travel confidently between theory and practice" (John, 2002, p. 337) resulting in greater use of higher level thinking. In the process, students grew accustomed to the necessary ambiguity (e.g. BU Center for Excellence and Innovation in Teaching, 2015) and progressed in their understanding of the application and implicit flexibility of theory. Lastly, and although Egleston (2013) reported that students have expressed some dislike for the less structured format that might accompany case-based learning, that was not an issue in this current study. At the conclusion of the assignment, and in agreement with Mayo (2002), students here were very favorable concerning CBI, as well as the interrupted format.

\section{Future Research}

Certainly the understanding and application of ICS will benefit not only from the necessary replications of the current study but also from consideration by other fields of study. The Up Series (Apted, 2013) used here could feasibly be used similarly in sociology or social psychology. For instance, a theoretical emphasis on attribution theory (e.g. Prud'homme-Genereauz, 2017), as opposed to developmental theory, would allow students to apply concepts such as locus of control or the persistence of social stereotypes, or to consider culture, poverty, and tradition from an ecological theory perspective.

Following an ICS format using intentionally selected books could also provide the desired ambiguous stepwise disclosure (Brooks, et al., 2012), the potential of empathic reaction (McFarlane, 2015), and a real-person-in-context setting (Ruggiero, 2002). Possibilities here might include Alvord's (2000) The Scalpel and the Silver Bear to explore the process of culture shock or Pausch's (2008) The Last Lecture as an ICS in discussions of bereavement of grief. The possibilities are certainly not limitless but they are indeed many, and would further the effort of seeking best practice with ICS.

\section{References}

Almutairi, A.F., Gardner, G.E., \& McCarthy, A. (2014). Practical guidance for the use of patternmatching technique in case-study research: A case presentation. Nursing and Health Sciences, 16, 239-244. doi:10.1111/nhs.12096

Ambrose, S.A., Bridges, M.W., DiPietro, M., Lovett, M.C., \& Norman, M.K. (2010). How learning works: Seven research-based principles for smart teaching. San Francisco: Jossey-Bass.

Anderson, B. (2017, October). Theoretical pattern-matching. The SoTL Advocate, Web log post at https://illinoisstateuniversitysotl.wordpress.com/2017/10/30/theoretical-pattern-matchingin-sotl-sotl-methods-series-1/

Anderson, B., Bradshaw, S., \& Banning, J. (2016). Using interrupted video case studies to teach developmental theory: A pilot study. Gauisus, 4. Retrieved from http://gauisus.weebly.

Journal of the Scholarship of Teaching and Learning, Vol. 19, No. 5, December 2019.

josotl.indiana.edu 
com/anderson-et-al---using-interrupted-video-case-studies-to-teach-developmental-theory-apilot-study.html

Anderson, B., Jorns, G.S., \& Bivens, L. (2017). Using interrupted case studies to address case study limitations. Paper presented to annual Teaching and Learning Symposium of the Center of Teaching and Learning Technology. Normal, IL.

Anderson, L.W., \& Krathwohl, D.R. (2001). A taxonomy for learning, teaching, and assessing: A revision of Blooms taxonomy of educational objectives. London: Longman, Inc.

Apted, M. (Director). (2013). The up series. London: First Runs and Features.

Bartsch, R.A. (2013a). Designing SoTL studies - Part 1: Validity. In R.A.R. Gurung \& J.H. Wilson (Eds.), Doing the scholarship of teaching and learning: Measuring systematic changes to teaching and improvements in learning. (pp. 17-34). San Francisco: Jossey-Bass.

Bishop-Clark, C. \& Dietz-Uhler, B. (2012). Engaging in the scholarship of teaching and learning: A guide to the process and how to develop a project from start to finish. Hemdon, VA: Stylus Publishing.

Brooks, R.M., Jyothsna, K.S., \& Mehmet, C. (2012). Interrupted case method for teaching ethics and transportation engineering and systems management course. Retrieved from https://peer.asee.org/interrupted-case-method-for-teaching-ethics-in-transportationengineering-and-systems-management-course.

BU Center for Excellence and Innovation in Teaching. (2015). Using case studies to teach. Retrieved from http://www.bu.edu/ceit/teaching-resources/using-case-studies-to-teach/

Casotti, G. Beneski, J. T., \& Knabb, M. T. (2013). Teaching physiology online: Successful use of case studies in a graduate course. Advances in Physiology Education, 37, 65-69. doi:10.1152/advan.00159.2012.

Divan, A., Ludwig, L., Matthews, K., Motley, P., \& Tomljenovic-Berube, A. (2017). Survey of research approaches utilized in the scholarship of teaching and learning publications. Teaching \& Learning Inquiry, 5(2). doi:10.20343/teachlearninqu.5.2.3.

Egleston, D.O. (2013). The interactive, progressive case study. Business Education Innovation Journal, 5(1), 101-104. Retrieved from http://beijournal.com/images/V5N1_Abstracts.pdf

Fink, L.D. (2003). Creating significant learning experiences: An integrated approach to designing college courses. San Francisco: John Wiley \& Sons.

Harrington, H.L. (1995). Fostering reasoned decisions: Case-based pedagogy and the professional development of teachers. Teaching \& Teacher Education, 11(3), 203-214. doi:10.1016/0742051X(94)00027-4

Harvard Law School. (2014). The case teaching method. Retrieved from http://casestudies.law.harvard.edu/the-case-study-teaching-method/.

Herreid, C.F. (2005). The interrupted case method. Journal of College Science Teaching, 35, 4-5. Retrieved from http://sciencecases.lib.buffalo.edu/cs/pdfs/Interrupted\%20Case\%20Method-XXXV2.pdf

Herreid, C.F. (2007). What makes a good case? In C.F. Herreid (Ed.), Start with the story: The case study method of teaching college science (pp. 45-48). Arlington: NSTA Press.

Herreid, C.F. (2011). Case study teaching. In W. Buskist, and J.E. Groccia (Eds.), Evidence-based teaching (pp. 31-40). Hoboken, NJ: Wiley.

Herreid, C.F. (2012). Can case studies be used to teach critical thinking? In C.F Herreid, N.A. Schiller, and K.F. Herreid (Eds.), Science stories: Using case studies to teach critical thinking (pp. 21-24). Arlington: NSTA Press.

Herreid, C.F., Schiller, N.A., \& Herreid, K.F. (2012). Science stories: Using case studies to teach critical thinking. Arlington, VA. National Science Teachers Assoc.

Journal of the Scholarship of Teaching and Learning, Vol. 19, No. 5, December 2019.

josotl.indiana.edu 
Hodges, L.C. (2005). From problem-based learning to interrupted lecture: Using case-based teaching in different class formats. Biochemistry and Molecular Biology Education, 33(2), 101-104. https://doi.org/10.1002/bmb.2005.494033022446

IDEA. (2017). Student ratings of instruction. Retrieved from http://www.ideaedu.org/Services/ Services-to-Improve-Teaching-and-Learning/Student-Ratings-of-Instruction

IDEA (2018). IDEA notes on instruction. Retrieved from https://www.ideaedu.org/ResourcesEvents/Teaching-Learning-Resources/IDEA-POD-Notes/Notes-on-Instruction

Irby, D.M. (1994). Three exemplary models of case-based teaching. Academic Medicine, 69 (12), 947 953.

John, P.D. (2002). The teacher educator's experience: Case studies of practical professional knowledge. Teaching and Teacher Education, 18(3), 323-341. Retrieved from http://ethos.bl.uk/OrderDetails.do?uin=uk.bl.ethos.297812

Kantar, L.D. (2013). Demystifying instructional innovation: The case of teaching with case studies. Journal of the Scholarship of Teaching and Learning, 13(2), 101-115. Retrieved from https://eric.ed.gov/?id=EJ1011686

Krathwohl, D.R. (2009) Methods of educational and social science research: The logic of methods (3 ${ }^{\text {rd }}$ ed.).Long Grove, IL: Waveland Press.

Law, D.D., Meyer, S., \& Fall, L. (2016). Using family science concept maps to gain higher order student learning outcomes. Family Science Review, 21(2), 116-134. Retrieved from http://www.familyscienceassociation.org/sites/default/files/6\%20\%20LAW\%20MEYER\%20FALL.pdf

Mayall, H.J. (2010). Integrating video case studies into a literacy methods course. International Journal of Instructional Media, 37(1), 33-41. Retrieved from https:/ / eds.a.ebscohost.com/eds/pdfviewer/pdfviewer?vid=34\&sid=85271328-abba-4e6ea2cb-87d6724b46f9\%40sessionmgr4009

Mayo, J.A. (2002). Case-based instruction: A technique for increasing conceptual application in introductory psychology. Journal of Constructivist Psychology, 15, 65-74.

Mayo, J.A. (2004). Using case-based instruction to bridge the gap between theory and practice in psychology of adjustment. Journal of Constructivist Psychology, 17, 137-146.

McFarlane, D.A. (2015). Guidelines for using case studies in the teaching-learning process. College Quarterly, 18(1). Retrieved from https:// eric.ed.gov/?id=EJ1070008

McKinney, K. (2007). Enhancing learning through the scholarship of teaching and learning. Bolton, MS: Anker Publishing.

Noorminish, A.I., Mirabloghasemi, M., Mustaffa, N.H., Latif, M.S., \& Buntat, Y. (2013). Student perception of using case study as a teaching tool. Social and Behavioral Sciences, 93, 2200-2204. https://doi.org/10.1016/j.sbspro.2013.10.187

Penn, M.L., Currie, C.S.M., Hoad, K.A., \& O’Brien, F.A. (2016). The use of case studies in OR teaching. Higher Education Pedagogies, 16-25. http://dx.doi.org/10.1080/23752696.2015.1134201

Perry, W.G. (1999). Forms of ethical and intellectual development in the college years: A scheme. San Francisco: Jossey-Bass.

Prud'homme-Genereauz, A. (2017). Formulating questions that address student misconceptions in a case study. Journal of College Science Teaching, 46(4), 54-60. Retrieved from http://www.nsta.org/store/product_detail.aspx?id=10.2505/4/jcst17_046_04_54 Quick Flip Questions for the Revised Blooms Taxonomy (2001). Madison, WI: Edupress.

Ulanoff, S.H., Fingon, J.C., \& Beltran, D. (2009). Using case studies to assess graduate's knowledge and skills in a graduate reading program. Teacher Education Quarterly, 36(2), 125-142. Retrieved from https://archive.org/details/ERIC_EJ857480

Journal of the Scholarship of Teaching and Learning, Vol. 19, No. 5, December 2019.

josotl.indiana.edu 
Valcke, M., De Wever, B., Zhu, C., \& Deed, C. (2009). Supporting active cognitive processing in collaborative groups: The potential of Bloom's taxonomy as a labeling tool. Internet and Higher Education, 12, 165-172. doi:10.1016/j.iheduc.2009.08.003

White, T.K., Whitaker, P., et al. (2009). The use of interrupted case studies to enhance critical thinking skills in biology. Journal of Microbiology \& Biology Education, 10(1), 25-31. doi:10.1128/jmbe.v10i1.96

Wilson-Doenges, G. (2013). Statistical models for analyzing learning data. In R.A.R Gurung \& J.H. Wilson (Eds.), Doing the scholarship of teaching and learning: Measuring systematic changes to teaching and improvements in learning. (pp. 49-58). San Francisco: Jossey Bass.

Yin, R.K. (2003). Applications of case study research ( $2^{\text {nd }}$ ed.). London: Sage.

Yin, R.K. (2009). Case study research: Design and methods (4 ${ }^{\text {th }}$ ed.). Thousand Oaks, CA: Sage.

Yin, R.K. (2014). Case study research: Design and methods ( $5^{\text {th }}$ ed.). London: Sage. 